Claremont Colleges

Scholarship@ Claremont

Pitzer Faculty Publications and Research

Pitzer Faculty Scholarship

$1-1-2009$

\title{
Why Did Lagrange "Prove" the Parallel Postulate?
}

Judith V. Grabiner

Pitzer College

\section{Recommended Citation}

Grabiner, Judith V. "Why Did Lagrange "Prove" the Parallel Postulate?" The American Mathematical Monthly 116.1 (January 2009): 3-18.

This Article is brought to you for free and open access by the Pitzer Faculty Scholarship at Scholarship @ Claremont. It has been accepted for inclusion in Pitzer Faculty Publications and Research by an authorized administrator of Scholarship @ Claremont. For more information, please contact scholarship@cuc.claremont.edu. 


\section{Why Did Lagrange "Prove" the Parallel Postulate?}

\section{Judith V. Grabiner}

1. INTRODUCTION. We begin with an often-told story from the Budget of Paradoxes by Augustus de Morgan: "Lagrange, in one of the later years of his life, imagined" that he had solved the problem of proving Euclid's parallel postulate. "He went so far as to write a paper, which he took with him to the [Institut de France], and began to read it."

But, De Morgan continues, "something struck him which he had not observed: he muttered 'Il faut que j'y songe encore' [I've got to think about this some more] and put the paper in his pocket" [8, p. 288].

Is De Morgan's story true? Not quite in that form. But, as Bernard Cohen used to say, "Truth is more interesting than fiction." First, according to the published minutes of the Institut for 3 February 1806, "M. Delagrange read an analysis of the theory of parallels" [25, p. 314; italics added]. Those present are listed in the minutes: Lacroix, Cuvier, Bossut, Delambre, Legendre, Jussieu, Lamarck, Charles, Monge, Laplace, Haüy, Berthollet, Fourcroy—a most distinguished audience!

Furthermore: Lagrange did not throw his manuscript away. It survives in the library of the Institut de France [32]. There is a title page that says, in what looks to me like Lagrange's handwriting, "On the theory of parallels: memoir read in 1806," together with the signatures of yet more distinguished people: Prony and Poisson, along with Legendre and Lacroix. The first page of text says, again in Lagrange's handwriting, that it was "read at the Institut in the meeting of 3 February 1806."

It is true that Lagrange never did publish it, so he must have realized there was something wrong. In another version of the story, told by Jean-Baptiste Biot, who claims to have been there (though the minutes do not list his name), everybody there could see that something was wrong, so Lagrange's talk was followed by a moment of complete silence [2, p. 84]. Still, Lagrange kept the manuscript with his papers for posterity to read.

This episode raises the three questions I will address in this article. First, what did Lagrange actually say in this paper? Second, once we have seen how he "proved" the parallel postulate, why did he do it the way he did? And last, above all, why did Joseph-Louis Lagrange, the consummate analyst, creator of the Analytical Mechan$i c s$, of Lagrange's theorem in group theory and the Lagrange remainder of the Taylor series, pioneer of the calculus of variations, champion of pure analysis and foe of geometric intuition, why did Lagrange risk trying to prove Euclid's parallel postulate from the others, a problem that people had been unsuccessfully trying to solve for 2000 years? Why was this particular problem in geometry so important to him?

I think that the manuscript is interesting in its own right, but I intend also to use it to show how Lagrange and his contemporaries thought about mathematics, physics, and the universe. As we will see, this was not the way we view these topics today.

2. THE CONTENTS OF LAGRANGE'S 1806 PAPER. First, we look at the contents of the paper Lagrange read in 1806. The manuscript begins by asserting that the theory of parallels is fundamental to all of geometry. Notably, that includes the 
facts that the sum of the angles of a triangle is two right angles, and that the sides of similar triangles are proportional. But Lagrange agreed with both the ancients and moderns who thought that the parallel postulate should not be assumed, but needed to be proved.

To see why people wanted to prove the parallel postulate, let us recall Euclid's five geometric postulates [9, pp. 154-155]. The first is that a straight line can be drawn from any point to any other point; the second, that a finite straight line can be produced to any length; the third, that a circle can be drawn with any point as center and any given radius; the fourth, that all right angles are equal; and the fifth, the so-called parallel postulate, which is the one in question. Euclid's parallel postulate is not, as a number of writers wrongly say (e.g., [5, p. 126]), the statement that only one line can be drawn parallel to a given line through an outside point. Euclid's postulate states that, if a straight line falls on two straight lines making the sum of the interior angles on the same side of that line less than two right angles, then the two straight lines eventually meet on that side. Euclid used Postulate 5 explicitly only once: to prove that if two lines are parallel, the alternate interior angles are equal. Of course, many later propositions rest on this theorem, and thus presuppose the parallel postulate.

Already in antiquity, people were trying to prove Postulate 5 from the others. Why? Of course one wants to assume as little as possible in a demonstrative science, but few questions were raised about Postulates 1-4. The historical focus on the fifth postulate came because it felt more like the kind of thing that gets proved. It is not self-evident, it requires a diagram even to explain, so it might have seemed more as though it should be a theorem. In any case, there is a tradition of attempted proofs throughout the Greek and then Islamic and then eighteenth-century mathematical worlds. Lagrange followed many eighteenth-century mathematicians in seeing the lack of a proof of the fifth postulate as a serious defect in Euclid's Elements. But Lagrange's criticism of the postulate in his manuscript is unusual. He said that the assumptions of geometry should be demonstrable "just by the principle of contradiction" - the same way, he said, that we know the axiom that the whole is greater than the part [32, p. 30R]. The theory of parallels rests on something that is not self-evident, he believed, and he wanted to do something about this.

Now it had long been known - at least since Proclus in the fifth century - that the "only one parallel" property is an easy consequence of Postulate 5. In the eighteenth century, "only one parallel" was adopted as a postulate by John Playfair in his 1795 textbook Elements of Geometry and by A.-M. Legendre in his highly influential Elements of Geometry [34]. So this equivalent to Postulate 5 had long been around; in the 1790s people focused on it, and so did Lagrange. But Lagrange, unlike Playfair and Legendre, didn't assume the uniqueness of parallels; he "proved" it. Perhaps now the reader may be eager to know, how did Lagrange prove it?

Recall that Lagrange said in this manuscript that axioms should follow from the principle of contradiction. But, he added, besides the principle of contradiction, "There is another principle equally self-evident," and that is Leibniz's principle of sufficient reason. That is: nothing is true "unless there is a sufficient reason why it should be so and not otherwise" [42, p. 31; italics added]. This, said Lagrange, gives as solid a basis for mathematical proof as does the principle of contradiction [32, p. 30V].

But is it legitimate to use the principle of sufficient reason in mathematics? Lagrange said that we are justified in doing this, because it has already been done. For example, Archimedes used it to establish that equal weights at equal distances from the fulcrum of a lever balance. Lagrange added that we also use it to show that three equal forces acting on the same point along lines separated by a third of the circumference of a circle are in equilibrium [32, pp. 31R-31V]. 
Now we are ready to see how Lagrange deduced the uniqueness of parallels from the principle of sufficient reason.

Suppose DE is drawn parallel to the given line $\mathrm{AB}$ through the given point $\mathrm{C}$. Now suppose the parallel DE isn't unique. Then we can also draw FG parallel to AB. (See Figure 1a.) But everything ought to be equal on each side, Lagrange said, so there is no reason that FG should make, with DE, the angle ECG on the right side; why not also on the left side? So the line HCI, making the angle DCH equal to angle ECG, ought also to be parallel to AB. One can see why the argument so far seemed consistent with Lagrange's views on sufficient reason.
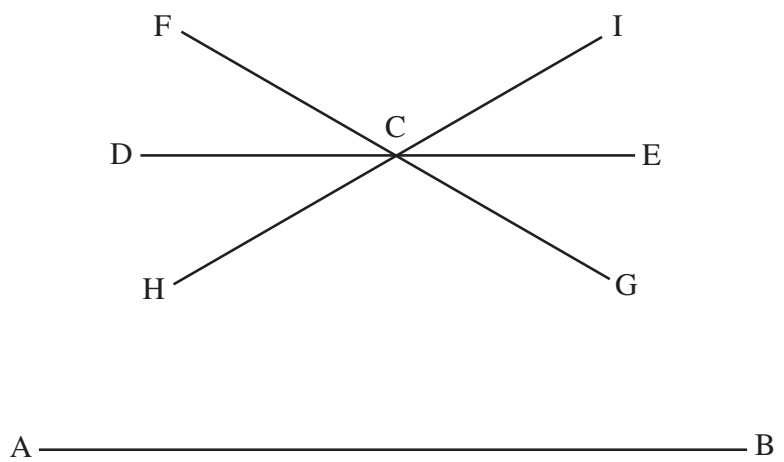

Figure 1a. Lagrange's proof, step 1.

By the same procedure, he continued, we can now make another line KL that makes angle HCK equal to angle ICG, but placed on the other side of the new parallel line HI (see Figure 1b); and we can keep on in this way to make arbitrarily many in this fashion (see Figure 1c), which, as he said, "is evidently absurd" [32, pp. 32V-33R].

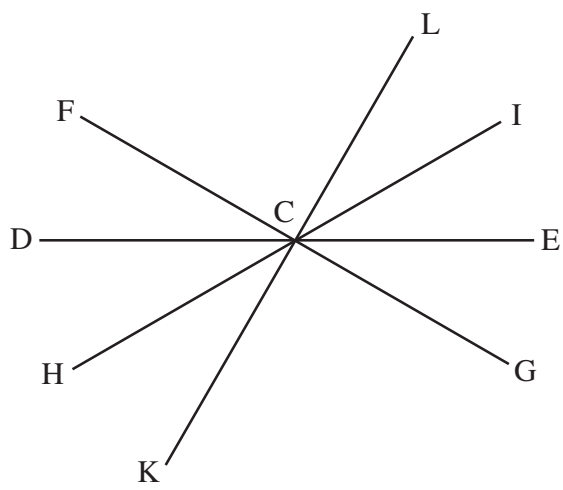

$\mathrm{A}$ B

Figure 1b. Lagrange's proof, step 2.

The modern reader may object that Lagrange's symmetry arguments are, like the uniqueness of parallels, equivalent to Euclid's postulate. But the logical correctness, or lack thereof, of Lagrange's proof is not the point. (In this manuscript, by the way, Lagrange went on to give an analogous proof-also by the principle of sufficient reason - that between two points there is just one straight line, because if there were a 


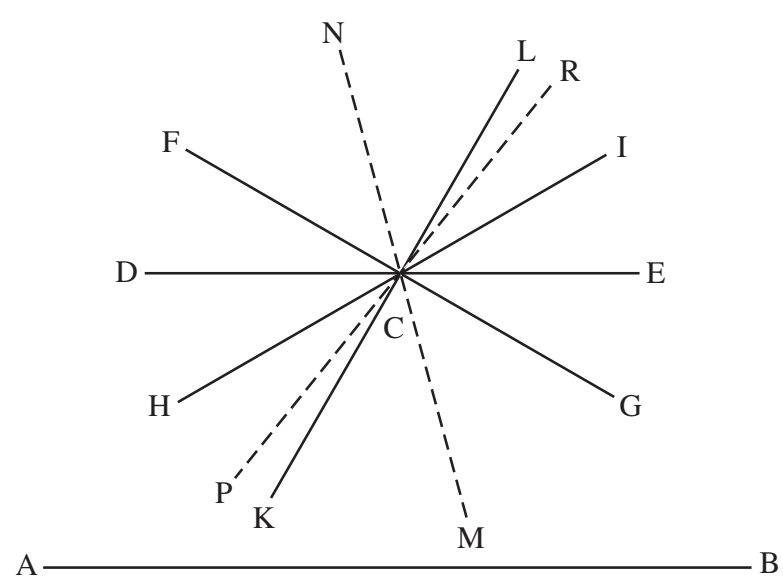

Figure 1c. Lagrange's proof, last step.

second straight line on one side of the first, we could then draw a third straight line on the other side, and so on [32, pp. 34R-34V]. Lagrange, then, clearly liked this sort of argument.)

3. WHY DID HE ATTACK THE PROBLEM THIS WAY? It is now time to address the second, and more important question: Why did he do it in the way he did?

I want to argue this: Lagrange's arguments from sufficient reason were shaped by properties of space, space as it was believed to be in the seventeenth and eighteenth centuries. These properties are profoundly Euclidean. To eighteenth-century thinkers, space was infinite, it was exactly the same in all directions, no direction was privileged, it was like the plane in having no curvature, and symmetrical situations were equivalent. Lagrange himself explicitly linked his symmetry arguments to Leibniz's principle of sufficient reason, but — as we will see-these ideas are also historically linked to Giordano Bruno's arguments for the infinite universe, Descartes' view of space as indefinite material extension, the projective geometry used to describe perspective in Renaissance art, various optimization arguments like "light travels in straight lines because that is the shortest path," and, above all, the Newtonian doctrine of absolute space. As we will soon see, these properties were essential to physical science in the seventeenth and eighteenth centuries: both physics and philosophy promoted the identification of space with its Euclidean structure.

This goes along with a shift in emphasis concerning what Euclidean geometry is about. Geometry, in ancient times, was the study of geometric figures: triangles, circles, parallelograms, and the like, but by the eighteenth century it had become the study of space [41, chapter 5]. The space eighteenth-century geometry was about was, in Henri Poincaré's words, "continuous, infinite, three-dimensional, homogeneous and isotropic" [44, p. 25]. Bodies moved through it preserving their sizes and shapes. The possible curvature of three-dimensional space did not even occur to eighteenth-century geometers. Their space was Euclidean through and through.

Why did philosophers conclude that space had to be infinite, homogeneous, and the same in all directions? Effectively, because of the principle of sufficient reason. For instance, Giordano Bruno in 1600 argued that the universe must be infinite because there is no reason to stop at any point; the existence of an infinity of worlds is no less reasonable than the existence of a finite number of them. Descartes used similar reasoning in his Principles of Philosophy: "We recognize that this world... has no 
limits in its extension.... Wherever we imagine such limits, we ...imagine beyond them some indefinitely extended space" [28, p. 104]. Similar arguments were used by other seventeenth-century authors, including Newton. Descartes identified space and the extension of matter, so geometry was, for him, about real physical space. But geometric space, for Descartes, had to be Euclidean. This is because the theory of parallel lines is crucial for Descartes' analytic geometry — not for Cartesian coordinates, which Descartes did not have, but because he needed the theory of similar figures in order to give meaning to expressions of arbitrary powers of $x$ [23, p. 197]. Descartes was the first person to justify using such powers. But an expression like $x^{4}$ for Descartes is not the volume of a 4-dimensional figure, but a line, which can be defined as the fourth proportional to the unit line, $x$, and $x^{3}$. That is, $1 / x=x^{3} / x^{4}$. They are all lines, and since all powers of $x$ are lines, they can all be constructed geometricallybut only if we have the theory of similar triangles, for which we need the theory of parallels.

Now let us turn from seventeenth-century philosophy to seventeenth-century physics. Descartes, some 50 years before Newton published his first law of motion, was a co-discoverer of what we call linear inertia: that in the absence of external influences a moving body goes in a straight line at a constant speed. Descartes called this the first law of nature, and for him, this law follows from what we now recognize as the principle of sufficient reason. Descartes said, "Nor is there any reason to think that, if [a part of matter] moves. .. and is not impeded by anything, it should ever by itself cease to move with the same force" [30, p. 75]. And the straight-line motion of physical moving bodies obviously requires the indefinite extendability of straight lines and thus indefinitely large, if not infinite, space [23, p. 97].

Descartes' contemporary Pierre Gassendi, another co-discoverer of linear inertia, used "sufficient reason" to argue for both inertia and the isotropy of space. Gassendi said, "In principle, all directions are of equal worth," so that in empty spaces, "motion, in whatever direction it occurs... will neither accelerate nor retard; and hence will never cease" [29, p. 127].

Artists, too, helped people learn to see space as Euclidean. We see the space created in the paintings and buildings of the Renaissance and later as Euclidean. Renaissance artists liked to portray floors with rectangular tiles and similar symmetric architectural objects - to show how good they were at perspective. These works of art highlight the observations that parallel lines are everywhere equidistant, that two lines perpendicular to a third line are parallel to each other. And our experience of perspective in art and architecture helps us shape the space we believe we live in. (See Figures 2, 3, and 4.) We have seen pictures like these many times, but consider them now as conditioning people to think in a particular way about the space we live in: as Euclidean, symmetric, and indefinitely extendible-going on to infinity [11].

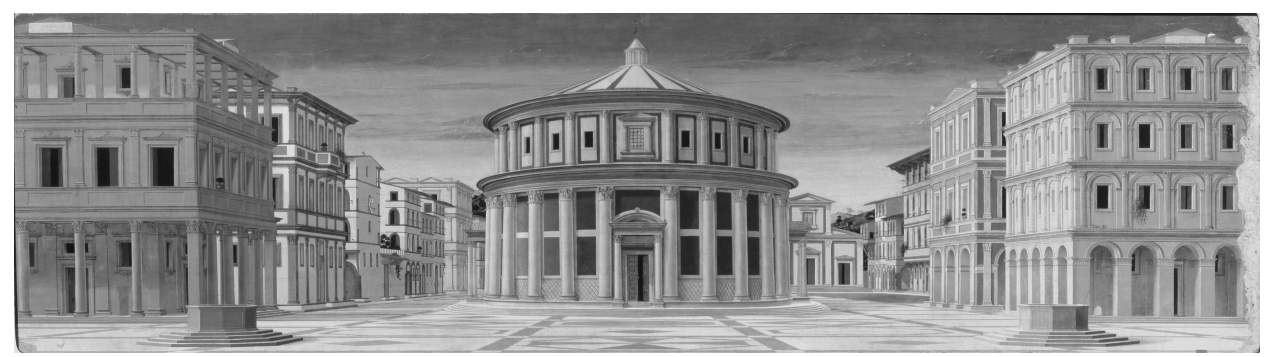

Figure 2. Piero della Francesca (1410/1420-1492), "The Ideal City." 


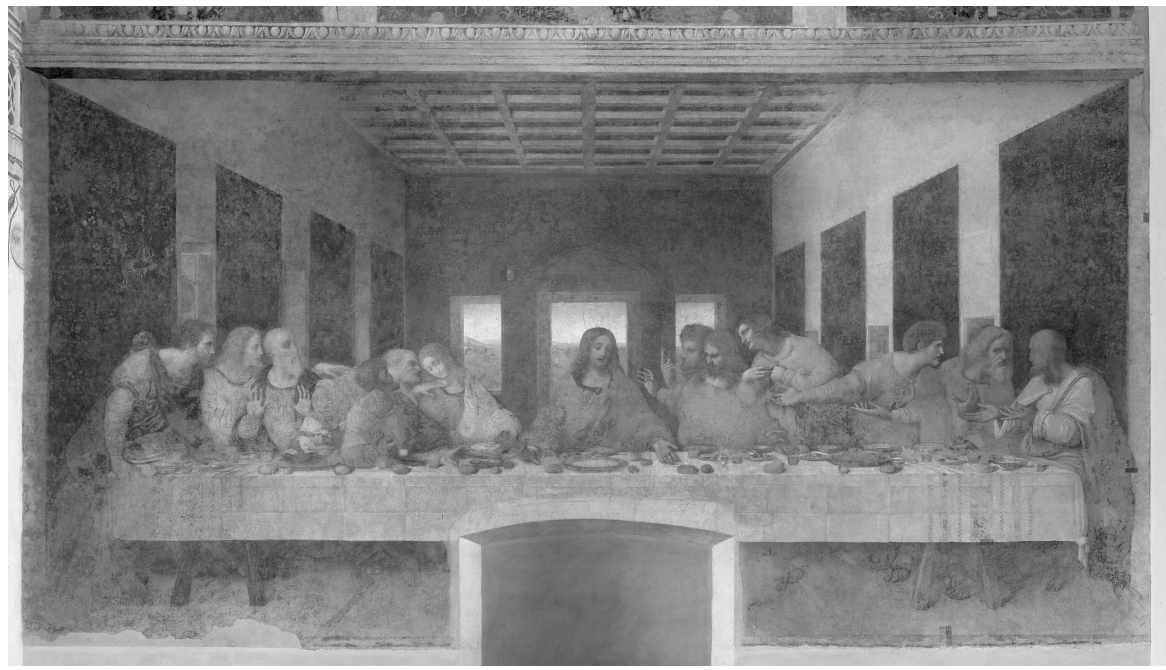

Figure 3. Leonardo da Vinci (1452-1519), "The Last Supper."

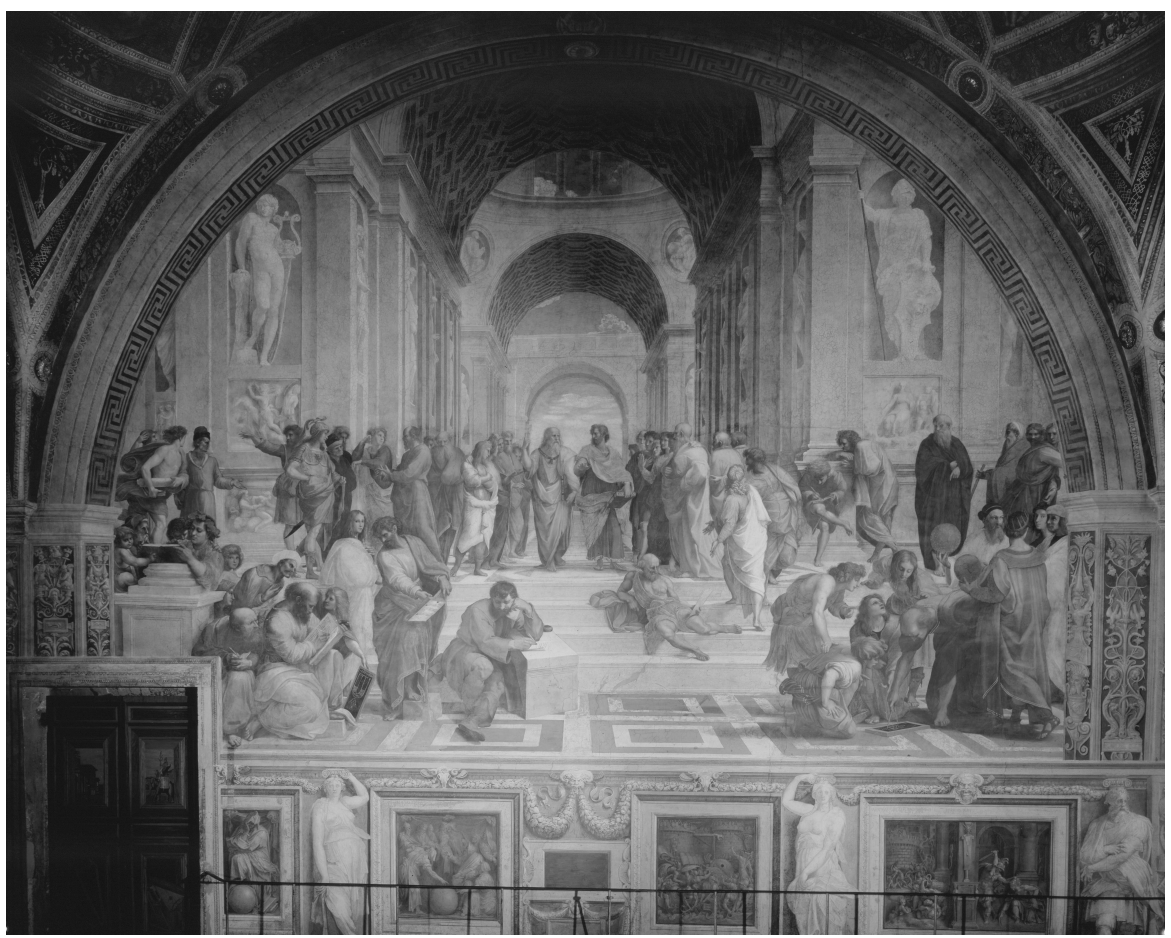

Figure 4. Raphael (1483-1520), "The School of Athens."

Artist-mathematicians like Piero della Francesca began the development of the subject of projective geometry, but the first definitive mathematical treatise on it is that of Girard Desargues in the 1630s. Seventeenth-century projective geometry used the cone (like the artist's rays of sight or light) to prove properties of all the conic sections as projections of the circle. For instance, geometers treated the ellipse as the circle projected to a plane not perpendicular to the cone. And the parabola, as Kepler pointed 
out, behaves projectively like an ellipse with one focus at infinity. So projective geometry explicitly brought infinity into Euclidean geometry: planes and lines go to infinity; parallel lines meet at the point at infinity.

And the geometry of perspective and projective geometry reinforced Euclideanness in a wide variety of other ways, from the role of Euclid's Optics in the humanistic classical tradition to the use of the theory of parallels to draw military fortifications from 2-dimensional battlefield sketches [12, p. 24].

Although these Euclidean views prevailed, perhaps they didn't have to. There were alternatives suggested even in the eighteenth century [22]. Is visual space Euclidean? Not necessarily. Bishop Berkeley, for instance, said that we don't "see" distance at all; we merely infer it from the angles we do see. And Thomas Reid pointed out that a straight line right in front of you looks exactly like a circle curved with you at the center-or even a circle curved away from you in the other direction. Reid gave a set of rules for visual space — he called this the "geometry of visibles" — which clearly are not Euclid's rules; a modern philosopher has called Reid's geometry of visibles "the geometry of the single point of view" [46, p. 396].

And there are other alternatives to Euclideanness. Cultures other than the western often speak about space differently and order their perceptions differently: particular directions have special connotations, and "closeness" can be cultural as well as metrical. Many cultures do not use the idea of an outside abstract space at all; instead-as Leibniz did — they recognize only the relations between bodies [3], [35], [36]. So, as a matter of empirical fact, abstract Euclidean space is not something that all human thinkers do use, let alone that all humans must use.

In the twentieth century, experimental psychologists showed that when people in a dark room are asked to put luminous points into two equidistant lines, or two parallel lines, the people are satisfied when the lines in fact curve away from the observer. As a result, Rudolf Luneburg in the 1940s claimed that visual space is a hyperbolic space of constant curvature; later psychological experiments suggest that visual space is not represented by any consistent geometry [48, pp. 30-31].

Even in the Renaissance, some painters portrayed what we now recognize as 3-dimensional non-Euclidean spaces, using reflections in a convex mirror, notably Parmigianino's (1524) "Self Portrait in a Convex Mirror," and, most famously, the "Arnolfini Wedding" by Jan van Eyck (1434). (See Figures 5, 6a, and 6b.) In the spaces in these mirrors, parallel lines are not everywhere equidistant.

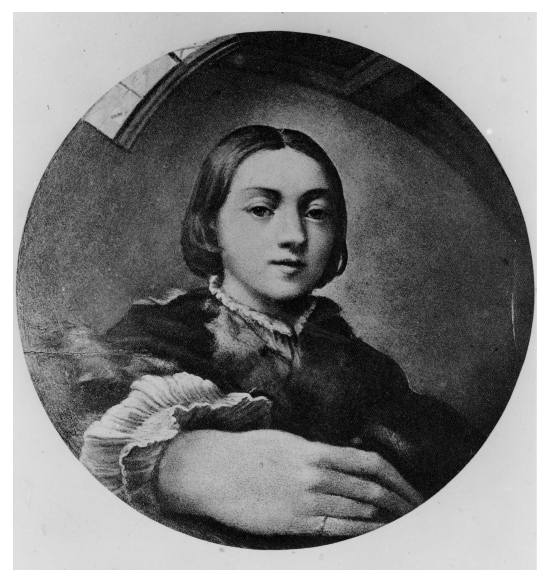

Figure 5. Parmigianino (1503-1540), "Self Portrait in a Convex Mirror." 


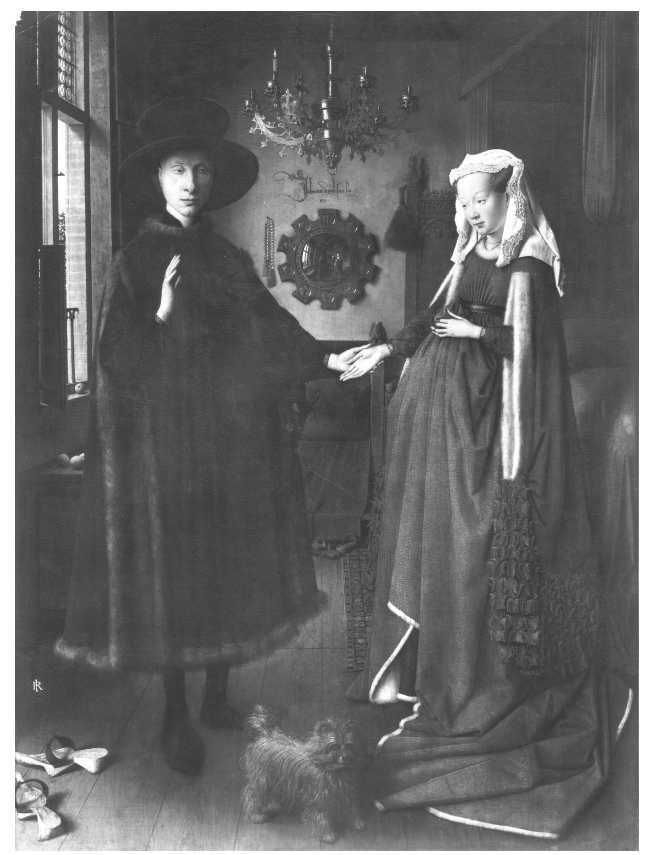

Figure 6a. Jan van Eyck (c. 1390-1441), "The Arnolfini Wedding."

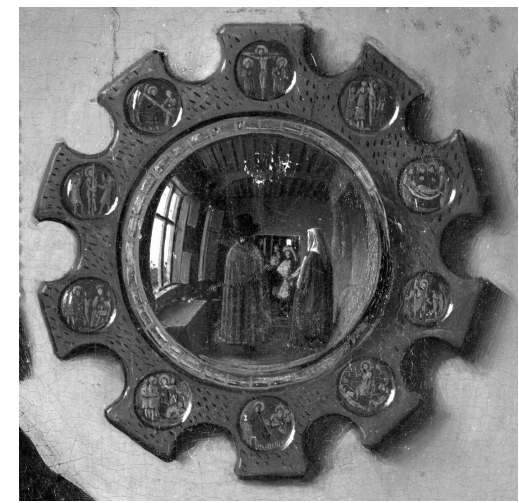

Figure 6b. Detail from "The Arnolfini Wedding."

A modern physicist, John Barrow, has said that if people had paid more attention to these mirrors, non-Euclidean geometry might have been discovered much sooner $[1$, p. 176]. But I am not so sure. I think that these artists viewed convex mirrors as presenting an especially difficult problem in portraying 3-dimensional Euclidean space on a 2-dimensional Euclidean canvas; for instance, J. M. W. Turner included such drawings in his strongly Euclidean lectures [45] on perspective. (See Figures 7a, 7b.)

The winning view, I think, is that expressed by the Oxford art historian Martin Kemp, who says that from the Renaissance to the nineteenth century, the goal of constructing "a model of the world as it appears to a rational, objective observer" [27, p. 314] was shared by scientists and artists alike. Virtually unanimously, artists, armed with Euclid's Optics, have long helped teach us to "see" a Euclidean world. 


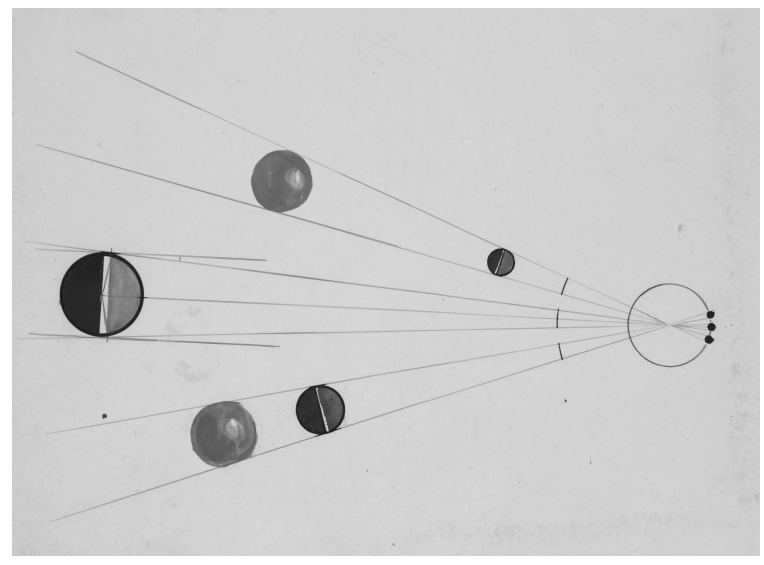

Figure 7a. J. M. W. Turner (1775-1851), "Spheres at Different Distances from the Eye." (c) Tate, London 2008.

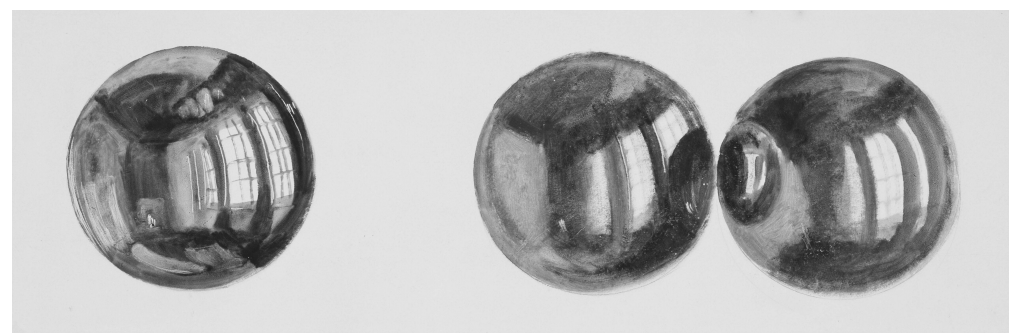

Figure 7b. J. M. W. Turner, "Reflections in a Single Metal Globe and in a Pair of Polished Metal Globes." (C) Tate, London 2008.

4. THE CRUCIAL ARGUMENT: NEWTONIAN PHYSICS. Let us now return to physics and to the most important seventeenth-century argument of all for the reality of infinite Euclidean space: Newtonian mechanics. Newton needed absolute space as a reference frame, so he could argue that there is a difference between real and apparent accelerations. He wanted this so he could establish that the forces involved with absolute (as opposed to relative) accelerations are real, and thus that gravity is real. Newton's absolute space is infinite and uniform, "always similar and immovable" [38, p. 6], and he described its properties in Euclidean terms. And it is real; it has a Platonic kind of reality.

Leibniz, by contrast, did not believe in absolute space. He not only said that spatial relations were just the relations between bodies, he used the principle of sufficient reason to show this. If there were absolute space, there would have to be a reason to explain why two objects would be related in one way if East is in one direction and West in the opposite direction, and related in another way if East and West were reversed [24, p. 147]. Surely, said Leibniz, the relation between two objects is just one thing! But Leibniz did use arguments about symmetry and sufficient reasonsufficient reason was his principle, after all. Thus, although Descartes and Leibniz did not believe in empty absolute space and Newton did, they all agreed that what I am calling the Euclidean properties of space are essential to physics.

In the eighteenth century, the Leibniz-Newton debate on space was adjudicated by one of Lagrange's major intellectual influences, Leonhard Euler. In his 1748 essay "Reflections on Space and Time," Euler argued that space must be real; it cannot be 
just the relations between bodies as the Leibnizians claim [10]. This is because of the principles of mechanics - that is, Newton's first and second laws. These laws are beyond doubt, because of the "marvelous" agreement they have with the observed motions of bodies. The inertia of a single body, Euler said, cannot possibly depend on the behavior of other bodies. The conservation of uniform motion in the same direction makes sense, he said, only if measured with respect to immovable space, not to various other bodies. And space is not in our minds, said Euler; how can physics-real physics - depend on something in our minds? So space for Euler is real.

The philosopher Immanuel Kant was influenced by Euler's analysis [14, pp. 29, 207]. Kant agreed that we need space to do Newtonian physics. But in his Critique of Pure Reason of 1781, Kant placed space in the mind nonetheless. We order our perceptions in space, but space itself is in the mind, an intuition of the intellect. Nevertheless, Kant's space turned out to be Euclidean too. Kant argued that we need the intuition of space to prove theorems in geometry. This is because it is in space that we make the constructions necessary to prove theorems. And what theorem did Kant use as an example? The sum of the angles of a triangle is equal to two right angles, a result whose proof requires the truth of the parallel postulate [26, "Of space," p. 423].

Even outside of mathematics and physics, explicit appeals to sufficient reason, symmetry, parallels, and infinity pervade eighteenth-century thought, from balancing chemical equations to symmetry in architecture to the balance of powers in the U.S. Constitution.

Let me call one last witness from philosophy: Voltaire. Like many thinkers in the eighteenth century, Voltaire said that universal agreement was a marker for truth. Religious sects disagree about many things, he said, so on these topics they are all wrong. But by contrast, they all agree that one should worship God and be just; therefore that must be true. Voltaire pointed out also that "There are no sects in geometry" [47, p. 195]. One does not say, "I'm a Euclidean, I'm an Archimedean." What everyone agrees on: that is what is true. "There is but one morality," said Voltaire, "as there is but one geometry" [47, p. 225].

\section{THE ARGUMENT FROM EIGHTEENTH-CENTURY MATHEMATICS} AND SCIENCE. Now let us turn to eighteenth-century mathematics and science. Eighteenth-century geometers tended to go beyond Euclid himself in assuming Euclideanness. As a first example, look at the 1745 Elémens de Géométrie by AlexisClaude Clairaut. Clairaut grounded geometry not on Euclid's postulates but on the capacity of the mind to understand clear and distinct ideas. For instance, Euclid had defined parallel lines as lines in the same plane that never meet. Clairaut, less interested in proof than in Euclidean plausibility, defined parallel lines as lines that are everywhere equally distant from one another [6, p. 10]. The great French Encyclopedia [7, vol. 11, pp. 905-906] defined parallel lines as "lines that prolonged to infinity never get closer or further from one another, or that meet at an infinite distance" [italics added] assuming, then, a uniform, flat Euclidean space infinitely extended. The "equidistant" definition of parallels is reinforced by ordinary language, as we speak of parallel developments, or, more geometrically, ships on parallel courses, and even of parallels of latitude.

And speaking of latitude raises the question of why the fact that the geometry on the surface of a sphere, with great circles serving as "lines," is not Euclidean-there are no parallels, for example_-did not shake mathematicians' conviction that all of Euclid's postulates are true and mutually consistent. Lagrange himself is supposed to have said that spherical trigonometry does not need Euclid's parallel postulate [4, pp. 52-53]. But the surface of a sphere, in the eighteenth-century view, is not non-Euclidean; it 
exists in 3-dimensional Euclidean space [20, p. 71]. The example of the sphere helps us see that the eighteenth-century discussion of the parallel postulate's relationship to the other postulates is not really about what is logically possible, but about what is true of real space.

Now, let us turn to eighteenth-century physics. As we will see, Euclideanness, especially the theory of parallels and the principle of sufficient reason, was essential to the science of mechanics in the eighteenth century, not only to its exposition, but to its progress.

Johann Heinrich Lambert was one of the mathematicians who worked on the problem of Postulate 5. Lambert explicitly recognized that he had not been able to prove it, and considered that it might always have to remain a postulate. He even briefly suggested a possible geometry on a sphere with an imaginary radius. But Lambert also observed that the parallel postulate is related to the law of the lever [20, p. 75]. He said that a lever with weightless arms and with equal weights at equal distances is balanced by a force in the opposite direction at the center equal to the sum of the weights, and that all these forces are parallel. So either we are using the parallel postulate, or perhaps, Lambert thought, some day we could use this physical result to prove the parallel postulate.

Lagrange himself in his Analytical Mechanics [31, pp. 4-5] gave an argument about balancing an isosceles triangle similar to, but much more complex than, Lambert's discussion. Lagrange himself did not explicitly link the law of the lever to the parallel postulate, but the geometry of the equilibrium situation that Lagrange was describing nonetheless requires it [4, pp. 182-183]. In a similar move, d'Alembert had tried to deduce the general law of conservation of momentum purely from symmetry principles [13, pp. 821-823]. And in the 1820s, J.-B. Fourier, from a very different philosophical point of view, also said that the parallel postulate could be derived from the law of the lever. From this Fourier concluded that geometry follows from statics and so geometry is a physical science [20, pp. 78-79]. But note that it is still Euclidean geometry.

Let us now concentrate further on Lagrange's mechanics. His deepest conviction was that a subject must be seen in its full generality. Like many Enlightenment thinkers only more so, Lagrange wanted to reduce the vast number of laws and principles to a single fundamental general principle, preferably one that is independent of experience. "Sufficient reason" was such a principle.

Although he did not explicitly cite Leibniz's principle in his Analytical Mechanics [43, p. 146], Lagrange used it frequently. For instance, he wrote, "The equilibrium of a straight and horizontal lever with equal weights and with the fulcrum at its midpoint is a self-evident truth because there is no reason that either of the weights should move."

Another key example of Euclideanness as physical argument is the use of parallelograms to find resultant forces. Lagrange, in his Analytical Mechanics, used the principle of sufficient reason, Euclid's theory of parallels, and the infinity of space and its Euclidean nature to discuss the composition of forces [31, p. 17]. He said that a body which is moved uniformly in two different directions simultaneously must necessarily traverse the diagonal of the parallelogram whose sides it would have followed separately. So parallels are needed. Lagrange continued, "with regard to the direction in the case of two equal forces, it is obvious that there is no reason that the resultant force should be nearer to one than the other of these two equal forces; therefore it must bisect the angle formed by these two forces" [31, p. 21]. Lagrange also used the principle of composition of forces to get the conditions of equilibrium when two parallel forces are applied to the extremities of a straight lever. He suggested that we imagine "that the directions of the forces extend to infinity" and then, on this basis, we can prove that "the resultant force must pass through the point of support." In effect 
this is the parallelogram argument with the corner of the parallelogram at infinity. Lagrange tried to reduce even his own fundamental physical principle - the principle of virtual velocities - to levers and parallelograms of forces, and after him Ampère, Carnot, Laplace, and Poisson tried to do the same [39, p. 218].

Pierre-Simon Laplace, too, related a priori arguments, including sufficient reason and Euclid's theory of parallels, to argue that physical laws had to be the way they were. For instance he said that a particle on a sphere moves in a great circle because "there is no reason why it should deviate to the right rather than the left of that great circle" - notice, "not a word about the forces acting on this particle on this sphere" [15, p. 104]. Laplace also asked why gravitation had to be inverse-square, and gave a geometric answer [4, p. 53], [16, p. 310]. He said that inverse-square gravitation implies that if the size of all bodies and all distances in the whole universe were to decrease proportionally, the bodies would describe the same curves that they do now, so that universe would still look exactly the same. The observer, then, needs to recognize only the ratios. So, Laplace said, even though we haven't proved Euclid's fifth postulate, we know it must be true, and so the theorems deduced from it must also be true. For Laplace, then, the idea of space includes the following self-evident property: similar figures have proportional sides $[4, \mathrm{p} .54]$. The Newtonian physical universe requires similar figures to have proportional sides, and this of course requires the theory of parallels, and thus geometry must be Euclidean [33, p. 472].

These men did not want to do mechanics, as, say, Newton had done. They wanted to show not only that the world was this way, but that it necessarily had to be. A modern philosophical critic, Helmut Pulte, has said that Lagrange's attempt to "reduce" mechanics to analysis strikes us today as "a misplaced endeavour to mathematize... an empirical science, and thus to endow it with infallibility" [39, p. 220]. Lagrange would have responded, "Right! That's just exactly what we are all doing." Lagrange thought these two things: Geometry is necessarily true; mechanics is mathematics. He needed them both.

6. WHY DID IT MATTER SO MUCH? And now, we are ready for the last question. Why did actually proving Postulate 5 matter so much to Lagrange and to his contemporaries? I trust I have convinced the reader of the central role of Euclideanness in the eighteenth century. But still, if it were just a matter of simple logic, surely after 2000 years people should have concluded: we have been trying as hard as possible, we cannot imagine how to prove this, so let us just concede defeat. It can't be done. Euclid was right in deciding that it had to be assumed as a postulate. Why did eighteenth-century geometers not settle for this, and, in particular, why didn't Lagrange?

Because there was so much at stake. Because space, for Newtonian physics, has to be uniform, infinite, and Euclidean, and because metaphysical principles like that of sufficient reason and optimality were seen both as Euclidean and as essential to eighteenth-century thought. How could all of this rest on a mere assumption? So, many eighteenth-century thinkers believed that it was crucial to shore up the foundations of Euclid's geometry, and we can place Lagrange's manuscript in the historical context of the many attempts in the eighteenth century to cure this "blemish" in Euclid by proving Postulate 5.

Also, Lagrange was not just any eighteenth-century mathematician. Lagrange was, mathematically speaking, a Cartesian and a Leibnizian. His overall philosophy of mathematics was to reduce each subject to the most general possible principle. In calculus, as I have argued at length in two books [17], [18], Lagrange wanted to reduce all the ideas of limits and infinites and infinitesimals and rates of change or fluxions to 
"the algebraic analysis of finite quantities." In algebra, Lagrange said that even Newton's idea of algebra as "universal arithmetic" wasn't general enough; algebra was the study of systems of operations. In mechanics, his goal was to reduce everything to the principle of virtual velocities - and then to use "only algebraic operations subject to a regular and uniform procedure" [31, preface]. Lagrange even composed his Analytical Mechanics without a single diagram, precisely so he could show he had reduced physics to pure analysis. Geometry, then, ought also to be reducible to self-evident principles, to clear, distinct, and general ideas.

Finally, there are social causes to be considered. First, the social background will help answer this question: Why was Lagrange doing this in 1806, as opposed, say, to the 1760s when he taught mathematics at the military school in Turin or in the 1770s and 1780s when he was the leading light of the Berlin Academy of Sciences? One reason is that in about 1800 there was a revival of interest in synthetic geometry in France. There was a Parisian school in synthetic geometry including Monge, Servois, Biot, Lacroix, Argand, Lazare Carnot and his students, and Legendre. Important reasons for this were partly practical, partly ideological [40, p. 450]. The practical needs are related to Monge's championing of descriptive geometry, so clearly useful in architecture and in military planning. Monge also helped directly to pique Lagrange's interest, writing two letters to him in the early 1790s soliciting his assistance on problems involving the geometry of perspective [37].

As for the ideology promoting geometry in France after the Revolution, as Joan Richards has written, "the quintessentially reasonable study of universally known space had a central role to play in educating a rational populace" [40, p. 454]. Lagrange himself articulated such views throughout his lifetime, writing as early as 1775 that synthetic geometry was sometimes better than analytic because of "the luminous clarity that accompanies it" [19, p. 135], and, near the end of his life, telling his friend Frédéric Maurice that "geometric considerations give force and clarity to judgement" [19, p. 1295].

So the French geometers would not have been favorably disposed to inventing a non-Euclidean geometry. It is no wonder that only comparative outsiders like the Hungarian Janos Bolyai and the Russian Nikolai Ivanovich Lobachevsky were the first to publish on this topic. Even Gauss, who out of fear of criticism did not publish his own invention of the subject that he christened "non-Euclidean geometry," was somewhat outside the French mathematical mainstream.

The British would not have found inventing non-Euclidean geometry enticing either. Even William Rowan Hamilton, who in the 1840s was to devise the first noncommutative algebra, wrote in 1837, "No candid and intelligent person can doubt the truth of the chief properties of Parallel Lines, as set forth by Euclid in his Elements, two thousand years ago.... The doctrine involves no obscurity nor confusion of thought and leaves in the mind no reasonable ground for doubt" [21, p. 354]. In fact, even after Hermann von Helmholtz and W. K. Clifford had introduced non-Euclidean geometry into Victorian Britain, some British thinkers continued to maintain that real space had to be Euclidean. There was a great deal at stake in Britain: the doctrine of the unity of truth, the established educational program based on the Euclidean model of reason, and the attitudes toward authority that this entailed.

The authority and rigor of Euclid, both in Britain and in France, were part and parcel of the established intellectual order. And-one last social point-non-Euclidean geometry even in the twentieth century was culturally seen as anti-establishment, partly through its association with relativity theory. For instance, surrealist artists used it that way: misunderstood, perhaps, but still explicitly part of their assault on traditional artistic canons. Two examples are Yves Tanguy's "Le Rendez-vous des parallèles" 


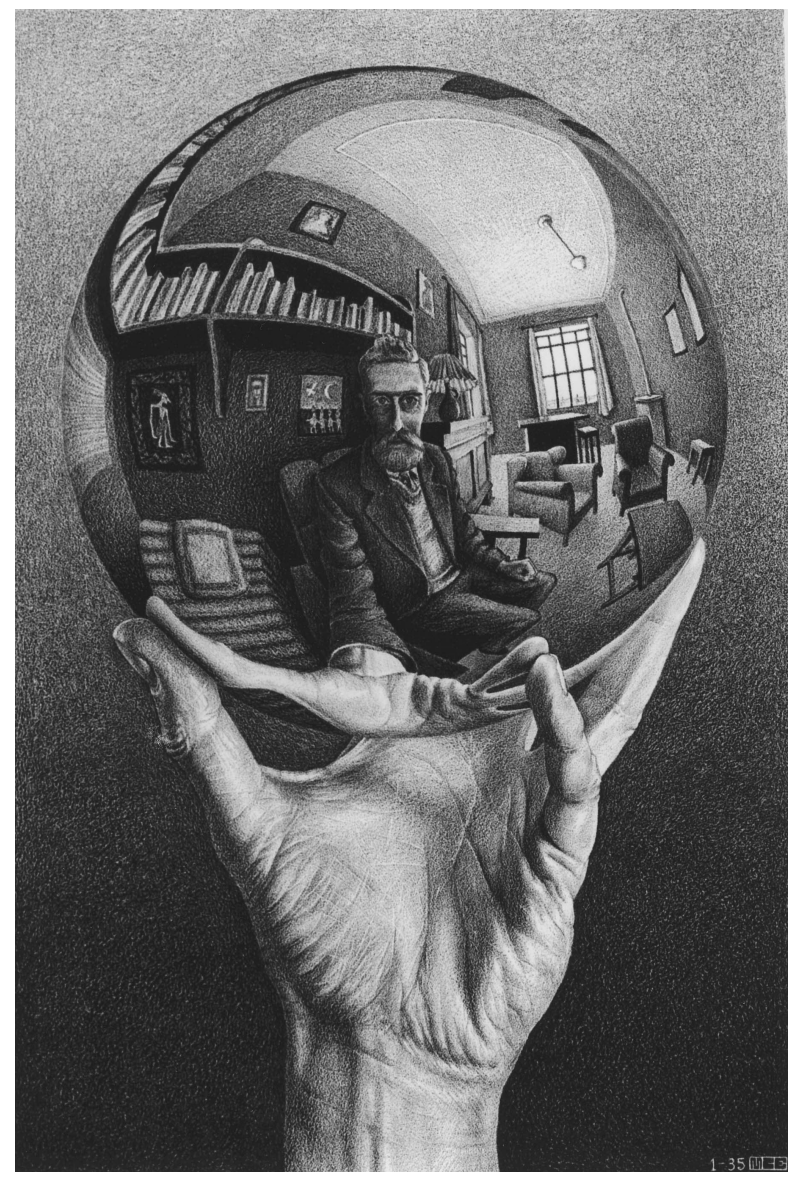

Figure 8. M. C. Escher (1898-1972), "Hand with Reflecting Sphere.” (c) 2008 The M.C. Escher CompanyHolland: All rights reserved.

(1935) and Max Ernst's "Young Man Intrigued by the Flight of a Non-Euclidean Fly" (1942-1947).

And Figure 8 shows an example from an artist who really did understand what a 3-dimensional non-Euclidean space might look like.

7. CONCLUSION. I cannot explain why Lagrange initially thought that his proof was a good one, but I hope it is clear why he thought he needed to prove the parallel postulate, and why he tried to prove it using the techniques that he used.

The story I have told reminds us that, although the great eighteenth-century mathematicians are our illustrious forbears, our world is not theirs. We no longer live in a world of certainty, symmetry, and universal agreement. But it was only in such a world that the work of Lagrange and Laplace, Fourier and Kant, Euler and d'Alembert could flourish. That space must be Euclidean was part of the Cartesian, Leibnizian, Newtonian, symmetric, economical, and totally rationalistic world view that underlies all of Lagrange's mathematics and classical mechanics-ideas that, from Newton and Leibniz through Kant and Laplace, buttressed the whole eighteenth-century view of the universe and the laws that govern it. And the certainty of Euclidean geometry was the model for the whole Enlightenment program of finding universally-agreed-upon truth through reason. 
Thus, though Lagrange's illustrious audience in Paris may have realized that his proof was wrong, their world-view made them unable to imagine that the parallel postulate couldn't be proved, much less to imagine that the world itself might be otherwise.

ACKNOWLEDGMENTS. I thank the Department of the History and Philosophy of Science, University of Leeds, England, for its hospitality and for vigorous discussions of this research. I also thank the Bibliothèque de l'Institut de France for permission to study Lagrange's manuscripts, the donors of the Flora Sanborn Pitzer Professorship at Pitzer College for their generous support, the Mathematical Association of America for inviting me to talk about this topic at MathFest 2007, and Miss Kranz, my trigonometry teacher at Fairfax High School in Los Angeles, who once on a slow day in class revealed to us all that there was such a thing as non-Euclidean geometry.

For the right to reproduce the works of art in this paper, I thank the following:

Figures 2, 3, 4, 5, 6a, 6b: Erich Lesser/Art Resource;

Figures 7a and 7b: The Tate Gallery, London;

Figure 8: M.C. Escher's "Hand with Reflecting Sphere" (c) 2008 The M.C. Escher Company-Holland: All rights reserved. www.mcescher.com

\section{REFERENCES}

1. J. D. Barrow, Outer space, in Space: In Science, Art and Society, F. Penz, G. Radick, and R. Howell, eds., Cambridge University Press, Cambridge, 2004, 172-200.

2. J.-B. Biot, Note historique sur M. Lagrange, in Mélanges Scientifiques et Littéraires, vol. III, Michel Lévy Frères, Paris, 1858, 117-124.

3. P. Bloom et al., Language and Space, MIT Press, Cambridge, MA, 1996.

4. R. Bonola, Non-Euclidean Geometry, Dover, New York, 1955.

5. R. Carnap, An Introduction to the Philosophy of Science, Dover, New York, 1995; reprint of Basic Books, New York, 1966.

6. A.-C. Clairaut, Éléméns de Géométrie, Par la Compagnie des Libraires, Paris, 1765.

7. J. D'Alembert and D. Diderot, eds., Encyclopédie, ou Dictionnaire Raisonné des Sciences, des Arts et des Métiers, Briasson, Paris, 1762-1772.

8. A. De Morgan, A Budget of Paradoxes, Longmans Green, London, 1872.

9. Euclid, The Thirteen Books of Euclid's Elements, T. L. Heath, ed., Cambridge University Press, Cambridge, 1956.

10. L. Euler, Reflexions sur l'espace et le tems, Mémoires de l'académie de Berlin 4 (1750) 324-333.

11. J. V. Field, The Invention of Infinity: Mathematics and Art in the Renaissance, Oxford University Press, Oxford, 1997.

12. J. V. Field and J. J. Gray, The Geometrical Work of Girard Desargues, Springer, New York, 1987.

13. J. Franklin, Artifice and the natural world: Mathematics, logic, technology, in Cambridge History of Eighteenth Century Philosophy, K. Haakonssen, ed., Cambridge University Press, Cambridge, 2006, 815-853.

14. M. Friedman, Kant and the Exact Sciences, Harvard University Press, Cambridge, MA 1992.

15. E. Garber, The Language of Physics: The Calculus and the Development of Theoretical Physics in Europe, 1750-1914, Birkhäuser, Boston, 1999.

16. C. C. Gillispie, Pierre-Simon Laplace, 1749-1827: A Life in Exact Science, in collaboration with R. Fox and I. Grattan-Guinness, Princeton University Press, Princeton, 1997.

17. J. V. Grabiner, The Calculus as Algebra: J.-L. Lagrange, 1736-1813, Garland, New York, 1990.

18. - The Origins of Cauchy's Rigorous Calculus, MIT Press, Cambridge, MA, 1981.

19. I. Grattan-Guinness, Convolutions in French Mathematics, 1800-1840, 3 vols., Birkhäuser, Basel, 1990.

20. J. Gray, Ideas of Space: Euclidean, Non-Euclidean and Relativistic, 2nd ed., Clarendon Press, Oxford, 1989.

21. T. L. Hankins, Algebra as pure Time: William Rowan Hamilton and the foundations of algebra, in Motion and Time, Space and Matter, P. Machamer and R. Turnbull, eds., Ohio State University Press, Columbus, $\mathrm{OH}, 1976,327-359$.

22. R. J. Herrnstein and E. G. Boring, A Source Book in the History of Psychology, Harvard University Press, Cambridge, MA, 1966.

23. L. Hodgkin, A History of Mathematics, Oxford University Press, Oxford, 2005. 
24. N. Huggett, ed., Space from Zeno to Einstein: Classic Readings with a Contemporary Commentary, MIT Press, Cambridge, MA, 1999.

25. Institut de France, Académie des Sciences, Procès-Verbaux des Séances de l'Académie, 1804-1807, vol. III, Académie des Sciences, Hendaye, 1913.

26. I. Kant, Critique of Pure Reason (trans. F. M. Müller), Macmillan, New York, 1961.

27. M. Kemp, The Science of Art: Optical Themes in Western Art from Brunelleschi to Seurat, Yale University Press, New Haven, CT, 1990.

28. A. Koyré, From the Closed World to the Infinite Universe, Johns Hopkins University Press, Baltimore, MD, 1957.

29. - Metaphysics and Measurement, Harvard University Press, Cambridge, MA, 1968.

30. - Newtonian Studies, University of Chicago Press, Chicago, IL, 1965.

31. J.-L. Lagrange, Analytical Mechanics, A. Boissonnade and V. N. Vagliente, trans. and eds., Kluwer, Dordrecht, 1997; from J.-L. Lagrange, Mécanique analytique, 2nd ed., Courcier, Paris, 1811-1815. In Oeuvres de Lagrange, Gauthier-Villars, Paris, 1867-1892, vol. XI.

32. - Sur la Théorie des Parallèles, Mémoire lu en 1806. Unpublished manuscript in the Bibliothèque de l'Institut de France, Inst MS 909, ff 18-35.

33. P.-S. Laplace, Exposition du système du monde, Cercle-Social l'An IV, Paris, 1796, in Ouevres complètes de Laplace, Gauthier-Villars, Paris, 1878-1912, vol. VI.

34. A.-M. Legendre, Eléments de Géométrie, Didot, Paris, 1794.

35. S. C. Levinson, Language and mind: Let's get the issues straight, in Language in Mind: Advances in the Study of Language and Thought, D. Gertner and S. Goldin-Meadow, eds., MIT Press, Cambridge, MA, 2003, 25-46.

36. - Frames of reference and Molyneux's question: Crosslinguistic evidence, in Language and Space, MIT Press, Cambridge, MA, 1996, 109-170.

37. G. Monge, Two letters to Lagrange, n. d., Oeuvres de Lagrange, Gauthier-Villars, Paris, 1867-1892, vol. XIV, 308-310, 311-314.

38. I. Newton, Sir Isaac Newton's Mathematical Principles of Natural Philosophy and His System of the World, trans. A. Motte, rev. F. Cajori, University of California Press, Berkeley, 1960.

39. H. Pulte, 1788: Joseph Louis Lagrange, Mechanique analitique, in Landmark Writings in Western Mathematics, 1640-1940, I. Grattan-Guinness, ed., Elsevier, Amsterdam, 2005, 208-224.

40. J. L. Richards, The Geometrical Tradition: Mathematics, Space, and Reason in the Nineteenth Century, in The Modern Physical and Mathematical Sciences, M. J. Nye, ed., Vol. 5 of the Cambridge History of Science, Cambridge University Press, Cambridge, 2003, 449-467.

41. B. A. Rosenfeld, A History of Non-Euclidean Geometry: Evolution of the Concept of a Geometric Space, Springer, Berlin and Heidelberg, 1988.

42. B. Russell, A Critical Exposition of the Philosophy of Leibniz, Allen and Unwin, London, 1937.

43. R. Taton, Lagrange et Leibniz: De la théorie des functions au principe de raison suffisante, in Beiträge zur Wirkungs- und Rezeptionsgeschichte von Gottfried Wilhelm Leibniz, A. Heinekamp, ed., Franz Steiner Verlag, Stuttgart, 1986, 139-147.

44. R. Torretti, Philosophy of Geometry from Riemann to Poincaré, D. Reidel, Boston, 1978.

45. J. M. W. Turner, drawings, in A. Fredericksen, Vanishing Point: The Perspective Drawings of J. M. W. Turner, Tate, London, 2004.

46. J. Van Cleve, Thomas Reid's geometry of visibles, Philosophical Review 111 (2002) 373-416.

47. F. M. Arouet de Voltaire, The Portable Voltaire, B. R. Redman, ed., Viking, New York, 1949.

48. M. Wagner, The Geometries of Visual Space, Erlbaum, Mahwah, NJ, 2006.

JUDITH V. GRABINER received her B.S. in Mathematics from the University of Chicago in 1960 and her Ph.D. in the History of Science from Harvard in 1966. She is the author of The Origins of Cauchy's Rigorous Calculus, MIT Press, Cambridge, MA, 1981, and The Calculus as Algebra, Garland, New York and London, 1990, to be reprinted, along with a number of her articles, by the MAA. For articles published in MAA journals, she has won the Carl Allendoerfer award three times and the Lester Ford award three times. In 2003 she was awarded the Deborah and Franklin Tepper Haimo Award for Distinguished College or University Teaching. She is the Flora Sanborn Pitzer Professor of Mathematics at Pitzer College, where her students keep her continually aware of the beauty of mathematics and the excitement of seeing its relationship with the world.

Department of Mathematics, Pitzer College, Claremont, CA 91711

jgrabiner@pitzer.edu 